\title{
A EVOLUÇÃO HISTÓRICA DAS FONTES BASILARES DOS DIREITOS FUNDAMENTAIS
}

THE HISTORICAL EVOLUTION OF THE SOUND SOURCES OF FUNDAMENTAL RIGHTS

Maicon Melito de Souza ${ }^{1}$

ISSUE DOI: $10.21207 / 1983.4225 .341$

\section{RESUMO}

O objetivo deste artigo é ordenar e explanar as fontes materiais e formais que serviram de base para a definição dos atuais direitos fundamentais, bem como para as próprias teorias dos direitos humanos e fundamentais. Por método qualitativo de análise jurídica e histórica são mapeadas as principais fontes que basearam o entendimento da fundamentalização dos direitos humanos, verificando a evolução dos direitos fundamentais. O resultado geral da pesquisa é o conhecimento das bases influenciadoras das normas fundamentais. Como resultado específico, a aquisição de parâmetros de reflexão para o alcance do sentido e da eficácia dos direitos fundamentais.

Palavras-chave: Fontes materiais. Fontes formais. Direitos Humanos. Direitos Fundamentais.

\footnotetext{
${ }^{1}$ Bacharel em direito pela Faculdade de Direito de Franca - FDF. Foi pesquisador voluntário de Iniciação Científica na FDF, membro do Núcleo de Estudos Constitucionais da Faculdade de Direito de Franca - Necon, e estagiário de Direito do Departamento de Assistência Judiciária da FDF.
} 


\section{INTRODUÇÃO}

A eficácia dos direitos fundamentais é a maior pretensão de um Estado democrático de direito, por isso são inúmeras as teorias que tratam da satisfação dessa pretensão. Entretanto, não é possível teorizar sobre determinada norma sem conhecer seu escopo originário.

$\mathrm{O}$ estudo das fontes dos direitos fundamentais tem por objetivo proporcionar ao teórico dos direitos humanos e fundamentais o conhecimento dos sentidos basilares das atuais normas, visto que o ordenamento jurídico baseia-se em princípios e normas anteriores à sua existência.

Do mesmo modo, é necessário o estudo das fontes dos direitos fundamentais para auxiliar o operador do direito na aplicação do sistema jurídico e na efetivação da justiça.

\section{A EVOLUÇÃO DAS FONTES MATERIAIS}

Os fatores da sociedade que fundamentam a essência das normas sociais podem ser entendidos como fontes materiais do Direito ${ }^{2}$. Esses fatores são baseados em valores consagrados como justos, pelos indivíduos ou pelas autoridades de determinado grupo.

A conservação da espécie humana como ser individual em seu estado de natureza primitiva nunca se mostrou viável em razão de sua pouca resistência como indivíduo singular. Diante disso, os seres humanos organizaram-se em grupos ordenados por valores em comum, estabelecendo pactos sociais. ${ }^{3}$

A necessidade de criação de medidas que possibilitassem a socialização harmoniosa dos mais variados grupos humanos em uma sociedade, deu origem ao direito, que, entre seus vários significados adquiridos no decorrer de séculos de estudo da dogmática jurídica, teve naquele momento o significado de regra e controle da conduta humana no meio social.

\footnotetext{
${ }^{2}$ MONTORO, André Franco. 1916-1999. Introdução à ciência do direito. 28. ed. rev. e atual. - São Paulo: Editora Revista dos Tribunais, 2009. p. 337.

${ }^{3}$ ROUSSEAU, J. J. - O contrato social. 3. Ed. - [tradução Danesi, A. P.]. São Paulo: Martins Fontes, 1996. (Clássicos). p. 17.
} 
Sobre o surgimento dos direitos fundamentais, é observável a influência cultural, principalmente através da religião e da filosofia, na formação dos ideais que posteriormente seriam base da construção do jusnaturalismo - crença de que o ser humano é titular de direitos inalienáveis que já nascem com ele, os direitos naturais. ${ }^{4}$

Com o passar das gerações e com o mundo cada vez mais interligado, as regras de caráter costumeiro de determinados grupos sociais foram sofrendo mutações em razão das mais variadas relações culturais, fatos que deram ensejo à concepção de direitos naturais a todos. $\mathrm{O}$ pensamento de que a existência humana não é um meio, mas sim um fim em si mesmo tornou-se prevalente entre os séculos XVII e XVIII. A crença não só na obrigação de não causar qualquer prejuízo injustificado às pessoas, mas agora também no dever de favorecer a felicidade dos demais foi a justificativa dos direitos comuns a todos, ou seja, os direitos humanos. ${ }^{5}$

A compreensão dos novos valores sociais mudou o significado do Direito, que passou a ser entendido não somente como norma de controle ou como a obrigação negativa de não fazer, mas também como norma de garantia do bem-estar e obrigação positiva de fazer. Decorrente disso, foi a percepção de que os direitos humanos são as pretensões mais importantes do ser humano, aquelas que garantem a preservação da espécie e da dignidade.

A partir do reconhecimento dos direitos humanos foram várias as transformações experimentadas por essas normas fundamentais, seja em relação ao conteúdo, à titularidade, ou ao plano da eficácia. A observação dos períodos de transformação dos direitos humanos é frequentemente referida pela expressão "teoria das gerações dos direitos humanos", a qual ganhou notoriedade pelas relações às exposições do jurista tcheco-francês Karel Vasak.

Embora sua importância seja quase inquestionável, a teoria geracional dos direitos humanos é muito criticada, principalmente pela utilização da expressão "gerações". Paulo Bonavides entende que a expressão pode dar a impressão errônea de substituição de uma geração por outra, pois os direitos humanos sofrem mutações periodicamente; entretanto, as

\footnotetext{
${ }^{4}$ HOBBES, Thomas, 1588 - 1679. Do Cidadão; [tradução, apresentação e notas Renato Janine Ribeiro; coordenação Roberto Leal Ferreira] - $2^{\circ}$ ed. - São Paulo: Martins Fontes, 1998. (Clássicos). p. 31.

${ }^{5}$ COMPARATO, Fábio Konder, 1936 - A afirmação histórica dos direitos humanos. 3. ed., rev. e ampl. - São Paulo: Saraiva, 2003. p. 26.
} 
mutações são complementativas, resultado da progressiva cumulação de valores pelas sociedades, não há alternância, mas aprimoramento de direitos. Em vista disso, o Autor utiliza o termo "dimensões", adotado aqui, por acreditar ser mais apropriado ao caráter complementativo e aprimorador dos períodos. ${ }^{6}$ Destaca-se que essa divergência é meramente terminológica, pois o método analítico, em síntese, é o mesmo.

Dividida em três gerações ou dimensões, a dita Teoria de Vasak associou os diferentes períodos ao lema da Revolução Francesa: liberté, égalité, fraternité, em português "liberdade, igualdade, fraternidade". Cada dimensão é relacionada com uma palavra do lema francês, conforme a melhor identificação com as inspirações axiológicas adotadas nos respectivos momentos históricos. ${ }^{7}$

A primeira dimensão dos direitos humanos é caracterizada pela expressão liberdade. O motivo dessa especificação é o ideal liberal da classe burguesa nas revoluções do século XVIII. Com alta persuasão econômica, até mesmo contra o poder absolutista europeu, era claramente prevalente o interesse da burguesia europeia, americana, e até mesmo mundial. Retrato de tal interesse é a busca pelos ingleses, franceses e estadunidenses da não intervenção estatal na área econômica, de proteção à propriedade privada, de garantias processuais e de igualdade puramente formal perante a lei, requisitos da filosofia liberalista. A busca pelo respeito aos direitos à vida e à liberdade deram o tom mais acentuado da influência jusnaturalista. Objetivamente, os direitos da primeira dimensão são de defesa e resistência perante o Estado, de finalidade negativa, pois a pretensão é de abstenção de definida conduta do Poder Público.

Os direitos da segunda dimensão são resultado dos anseios sociais provenientes das mazelas causadas pelo crescente processo de industrialização dos bens de consumo e a incisiva mercantilização globalizada. As consequências da revolução industrial no século XIX foram impactantes em todo o mundo, afetando de forma mais forte as classes econômicas mais baixas. A massificação dos meios de produção causou enorme êxodo da população rural para os grandes centros industriais. A aplicação de métodos rústicos de linhas de produção com a finalidade de reduzir custos, bem

\footnotetext{
${ }^{6}$ BONAVIDES, Paulo. Curso de Direito Constitucional. 9. ed. rev. atual. ampliada. (em apêndice texto da Constituição Federal de 1988, com a EC até a de n. 24, de 10.12.1999). São Paulo-SP: Malheiros, 2000. p. 517.

${ }^{7}$ VASAK, Karel. The international dimensions of Human Rights. Paris, Unesco, 1982. p. 671.
} 
como os abusos no expediente trabalhista, foram causas fundamentais da eclosão de manifestações da nova classe operária. Os atos revolucionários reivindicavam direitos trabalhistas, principalmente direitos de assistência social por parte do Estado, como saúde, educação e segurança. Exigem-se do Estado comportamentos ativos, de natureza positiva, visto que se cobra a participação estatal no bem-estar social. O período fica marcado pela expressão "igualdade", influência da filosofia socialista, que pregava a igualdade material para a realização da justiça.

Na terceira dimensão dos direitos humanos, a consequência fundamental para sua busca foram as atrocidades vividas pela espécie humana no século XX. As devastações causadas pela Segunda Guerra Mundial foram, sem dúvidas, os maiores motivos da população mundial para o pleito da fraternidade como princípio guiador nas relações sociais e individuais, dali a dimensão ser relacionada à expressão "fraternidade". As pretensões desejadas são os direitos à paz, ao desenvolvimento sustentável, ao respeito do exercício cultural e à autodeterminação dos povos. Nada obstante, os titulares diretos dos direitos não são as pessoas individualmente consideradas, e sim a coletividade de indivíduos — o povo e as nações. Sua distinção das demais dimensões é a essência coletiva e difusa, carregada de solidariedade e fraternidade.

Embora a Teoria de Vasak proponha três gerações de direitos humanos, parte da doutrina vem relatando uma suposta quarta geração de direitos, e em alguns casos até mesmo uma quinta geração, ainda não havendo consenso entre os estudiosos do assunto sobre essa existência. Entretanto, nada obsta de se fazer uma reflexão precisa sobre o assunto.

A quarta dimensão seria os direitos ligados à ética na biotecnologia, criando biodireitos. ${ }^{8}$ Para outros, é a efetiva participação cidadã nos movimentos democráticos, caminhando para mudanças institucionais, de radicalização nacionalista contra o neoliberalismo, e da organização das populações por meios eletrônicos de comunicação, que ensejaria o surgi-

${ }^{8}$ OLIVEIRA JÚNIOR, José Alcebíades de. Teoria jurídica e novos direitos. Rio de Janeiro: Lumen Juris, 2000. p. 83. 
mento de direitos de participação cidadã e de proteção no tráfego de informações dos aparatos digitais. ${ }^{9}$ Por fim, para uns é a proteção ao meio ambiente, dada a importância transindividual. ${ }^{10}$

Levando em conta o fato já mencionado de que os direitos humanos estão em constantes mutações, no sentido de aprimoramento do sistema, há quem acredite na quinta dimensão, que mesmo com as inúmeras interpretações, seria o desejo de tutelar todas as formas de vida, característica perceptível no crescimento cada vez maior do ativismo ambiental. ${ }^{11}$

Percebe-se o intuito orientador da teoria geracional dos direitos humanos, a qual direciona aos principais períodos de consolidação das pretensões dos diferentes grupos sociais. Prestigiada pela doutrina predominante, há requisitos que devem ser observados no momento da adoção de tal teoria. A falta de precisão histórica no relacionamento dos acontecimentos sociais com as efetivas consagrações dos direitos é algo a ser sempre lembrado, como também, as diferentes características culturais de cada grupo social, uma vez que direitos estabelecidos em um local podem ser reconhecidos em momentos completamente distintos de outra localidade. Assim, a teoria geracional é muito útil para os estudos, porém, deve ser utilizada com perspicácia.

\section{A EVOLUÇÃO DAS FONTES FORMAIS}

Ao longo deste subtítulo será abordado o processo histórico de formação e evolução dos direitos humanos, agora de maneira mais específica e formal, situando os principais eventos e documentos inspiradores dos mecanismos de fundamentação normativa e que ainda sustentam os direitos fundamentais.

Como fontes formais, entendem-se os dispositivos jurídicos que fundamentam as normas em vigor, atribuindo caráter de direito positivo. Em face disso, podemos classificá-las em fontes formais diretas e indiretas.

\footnotetext{
9 OLIVEIRA JÚNIOR, José Alcebíades de. Teoria jurídica e novos direitos. Rio de Janeiro: Lumen Juris, 2000. p. 514.

${ }^{10}$ TRINDADE, Antônio Augusto Cançado. Direitos humanos e meio-ambiente: paralelo dos sistemas de proteção internacional. - Porto Alegre: Sergio Antonio Fabris Editor, 1993. p. 23.

${ }^{11}$ SAMPAIO, José Adércio Leite. Direitos fundamentais: retórica e historicidade. Belo Horizonte: Del Rey, 2004. p. 302.
} 
As diretas, com sentido primordial, são as leis positivadas em suas várias espécies. As indiretas, com sentido subsidiário, são os costumes jurídicos, a jurisprudência e a doutrina. ${ }^{12}$

O surgimento de sociedades mais complexas fez crescente a necessidade de se socializar indivíduos de diversas naturezas, pois as diferenças de personalidade - de caráter, ideológicas e culturais - são característica do ser humano, por esse motivo, foram criadas normas com poder coercitivo e regulamentador das condutas contrárias aos valores da coletividade. ${ }^{13}$

Com o aperfeiçoamento do direito ao longo do tempo, os princípios humanos ordenadores, valorados sob a ótica da cultura de sua respectiva sociedade, direito natural, influenciaram a elaboração de normas formalizadas em documentos escritos, reunidos e codificados, direito positivo. Entretanto, para que se fosse assegurada a observância dos princípios ordenadores na codificação das normas fez-se mister a criação e positivação de uma norma caracterizada por sua supremacia, no que diz respeito a seu poder de vincular as demais leis ao seu conteúdo, surgiram com esse motivo os primeiros documentos legais com sentido de Constituição. ${ }^{14}$

As primeiras constituições não nasceram espontaneamente, como ideias concebidas de imediato, muito pelo contrário, surgiram sob a influência dos processos de evolução institucional dos Estados. A perda de força do sistema político medieval, baseado no absolutismo monárquico, foi parte do processo evolutivo, sendo um dos primeiros fatores que proporcionaram o esboço de uma constituição.

A legislação considerada pela eminente doutrina como pioneira do atual método constitucional, em razão de seu grande impacto histórico e social, é a Magna Carta, de 15 de junho de 1215, da Inglaterra. ${ }^{15}$ A relação já desgastada entre reis e barões feudais encontrou seu ápice no reinado de João Sem-Terra. Com o poder monárquico concentrado e os altos impostos, a nobreza se rebelou. Diante do forte poderio econômico dos burgueses, que exigiam a declaração formalizada de seus direitos e a limitação

12 MONTORO, André Franco. 1916-1999. Introdução à ciência do direito. 28. ed. rev. e atual. - São Paulo: Editora Revista dos Tribunais, 2009. p. 337.

${ }^{13}$ MACHADO NETO, A. L. - Sociologia Jurídica. 6. Ed. - São Paulo: Saraiva, 1987. p. 165.

${ }^{14}$ AZAMBUJA, Darcy, 1903 - 1970. Teoria geral do Estado. 44. ed., São Paulo: Globo, 2003. p. 2.

${ }^{15}$ DALLARI, Dalmo de Abreu, 1931 - Elementos de teoria geral do Estado. 20. ed. atual. - São Paulo: Saraiva, 1998. p. 72. 
do poder do rei, João Sem-Terra foi sucumbido a assinar a Magna Carta. Ressalta-se que a formalização dos direitos alcançou somente a nobreza, deixando de fora o povo. ${ }^{16}$

Outro marco importante do mecanismo de formalização dos direitos humanos de liberdade, que também influenciou a elaboração das futuras constituições, é o Habeas Corpus Act, de 27 de maio de 1679, Inglaterra. ${ }^{17}$ Embora o habeas-corpus já existisse na Inglaterra antes mesmo da Magna Carta, previsto como mandado judicial em casos de prisão arbitrária, a falta de regras processuais adequadas tornou sua eficácia como remédio judicial muito reduzida. ${ }^{18}$ Desse modo, o novo instituto veio sanar as imperfeições então vigentes, criando uma ação judicial específica para a defesa da liberdade cerceada arbitrariamente por autoridade. A Lei de Habeas Corpus, de 1679, baseou as legislações posteriores desse tema em todo o mundo, leis que aprimoraram as liberdades individuais, e passaram a tutelar qualquer constrangimento na liberdade de locomoção e dos direitos líquidos e certos. ${ }^{19}$

A evolução histórica e dogmática dos direitos humanos continuou se aprimorando ao longo dos tempos, como não poderia deixar de ser. O nascimento do constitucionalismo aproximava-se cada vez mais e o processo de formalização dos direitos se consolidava.

Foi em 16 de dezembro de 1689, na mesma Inglaterra da Magna Carta e da Lei de Habeas Corpus, a aprovação com força de lei da declaração de direitos reconhecida como Bill of Rights, apreciada como a nova

${ }^{16}$ COMPARATO, Fábio Konder. A Afirmação Histórica dos Direitos Humanos. São Paulo: Saraiva, 1999, apud Biblioteca Virtual de Direitos Humanos, Universidade de São Paulo. Magna Carta - 1215 (Magna Charta Libertatum). Disponível em $<\mathrm{http} / / / \mathrm{www}$.direitoshumanos.usp.br/index.php/Documentos-anteriores-\%C3\%A0cria\% $3 \% \mathrm{~A} 7 \% \mathrm{C} 3 \%$

A3o-da-Sociedade-das-Na\%C3\%A7\%C3\%B5es-at\%C3\%A9-1919/magna-carta-1215magna-charta-libertatum.html . Acesso em 2 de novembro de 15.

${ }^{17}$ MIRANDA, Pontes de. História e prática do habeas corpus; atualizado por Vilson Rodrigues Alves. - Campinas: Bookseller, 1999. p. 93.

${ }^{18}$ MACHADO, Antônio Alberto. Prisão cautelar e liberdades fundamentais. Rio de Janeiro: Lumen Juris, 2005. p. 255.

${ }^{19}$ COMPARATO, Fábio Konder, 1936 - A afirmação histórica dos direitos humanos. 3. ed., rev. e ampl. - São Paulo: Saraiva, 2003. p. 85. 
Magna Carta. ${ }^{20} \mathrm{O}$ documento declarava os direitos e liberdades das pessoas, a forma de sucessão da coroa inglesa, estabelecia a independência das eleições dos membros do parlamento e a liberdade de palavra nas discussões no exercício do cargo, ou seja, a imunidade parlamentar material. ${ }^{21}$

Com a formalização das primeiras legislações disciplinadoras das liberdades individuais na Inglaterra, que infelizmente não alcançavam todos os indivíduos, já que tutelavam o interesse das classes sociais dominantes, o constitucionalismo encontraria inspiração para a positivação mais efetiva e concreta dos direitos humanos de primeira dimensão.

A insatisfação com a força do poder dos governantes não foi exclusiva da sociedade inglesa. Curiosamente, seria a Inglaterra vitima de sua própria filosofia de política institucional. Com efeito, as insatisfações da classe burguesa das treze colônias britânicas na América do Norte com as restrições comerciais e os crescentes impostos estabelecidos pela metrópole inglesa foram o estopim para a Revolução Americana de 1776. A limitação do poder do governante, anteriormente regulamentada na metrópole, era também desejada pela colônia.

Foi em 12 de junho de 1776, com a Declaração de Direitos da Virgínia, uma das treze colônias e hoje Estado-membro dos Estados Unidos da América, que o constitucionalismo moderno de fato se iniciou. Caracterizada pela finalidade de positivar os direitos de liberdade e igualdade formal dos homens, é considerada o primeiro documento essencialmente constitucional, pois já estabelecia os princípios a serem seguidos no Estado e a delimitação do poder de governo. ${ }^{22}$

Com a independência das então colônias britânicas, por meio da Declaração Unânime dos Treze Estados Unidos da América - Declaração da Independência - em 4 de julho de 1776, a organização dos Estados independentes tornou-se fundamental para a preservação dos ideais revolucionários de limitação do poder governamental, igualdade formal e da prevalência da razão humana. Desse modo, o mecanismo constitucional con-

20 LEGISLATION.GOV.UK. Bill of Rights [1688]. Disponível em: http://www.legislation.gov.uk/aep/WillandMarSess2/1/2/introduction. Acesso em $4 \mathrm{de}$ novembro de 2015.

${ }^{21}$ DALLARI, Dalmo de Abreu, 1931 - Elementos de teoria geral do Estado. 20. ed. atual. - São Paulo: Saraiva, 1998. p. 168.

22 DIPPEL, Horst. História do constitucionalismo moderno: novas perspectivas. Tradução de António Manuel Hespanha e Cristina Nogueira da Silva. Lisboa: Fundação Calouste Gulbenkian, 2007. p. 4. 
tinuou a ser adotado, entretanto, não mais de forma específica de cada Estado confederado, e sim sob a égide do pacto federativo. A Constituição dos Estados Unidos, escrita em 1787, ratificada em 22 de junho de 1788 e em vigor desde 9 de março de 1789, transformou a Confederação em Federação, mas ainda não detalhava os direitos dos cidadãos (WHITE HOUSE, THE CONSTITUTION OF THE UNITED STATES OF AMERICA). A Carta dos Direitos dos Estados Unidos, Bill of Rights Americano, foi ratificada somente em 15 de dezembro de 1791 (THE LIBRARY OF CONGRESS, BILL OF RIGHTS).

É bom destacar que mesmo a Constituição estadunidense declarando como norma o direito de igualdade entre os seus cidadãos, igualdade apenas formal, tal enunciado é condizente apenas sob a lógica liberal de prestação negativa da primeira dimensão dos direitos humanos e fundamentais. A expressão "cidadãos" referia-se aos homens livres, não guardando da mesma maneira os direitos das mulheres, muito menos da população escrava dos Estados do Sul.

A importância do processo constitucional na América Inglesa é, sem dúvida, inquestionável. As declarações de direitos e as constituições dos novos Estados independentes foram documentos pioneiros da nova Era Constitucional, a qual não regulamentava somente a ordem institucional estatal, mas dava indícios de um modelo de Estado Democrático. A condição de Estado Constitucional Democrático passaria a ser buscada em outras várias Nações, sendo a luta da sociedade francesa a de maior repercussão.

A decadência do regime monárquico absolutista de direito divino não foi característica exclusiva dos britânicos, o mesmo fato também era notório na França do século XVIII. O estamento francês passou a ser duramente contestado pela classe burguesa, que via a culpa da derrocada econômica do País nos privilégios da nobreza e do clero, não obstante, as reflexões do regime político e dos direitos individuais feitas pelos intelectuais iluministas fundamentavam as aspirações de mudança. Estoura, em 1789, a Revolução Francesa. ${ }^{23}$

Com a instalação da Assembleia Nacional Constituinte francesa ocorreu, em 26 de agosto do mesmo ano da Revolução, a Declaração dos Direitos do Homem e do Cidadão, que tinha como diferencial a generalização dos direitos, ou mais precisamente, reconhecia que esses direitos

\footnotetext{
${ }^{23}$ MOTA, Myriam Becho. História: das cavernas ao terceiro milênio. 2. vol. 1. ed. - São Paulo: Moderna, 2005. p. 126.
} 
também eram inerentes a outros povos ${ }^{24}$. A igualdade formal era reproduzida logo no primeiro artigo, destacando-se ainda no artigo dezesseis o reconhecimento da Constituição como forma de fundamentação da ordem estatal e dos direitos individuais. Sendo assim, a Constituição Francesa de 1791, aprovada pela Assembleia Nacional Constituinte no dia 3 de setembro, seguiu os mesmo princípios, todavia, sendo contraditória ao adotar o sufrágio censitário, Section II do Chapitre Premier. ${ }^{25}$

A Revolução Francesa foi um dos maiores marcos da sociedade moderna, pois deu início a quebra de paradigmas do dito "primeiro mundo", em um de seus Estados mais eminentes. Através dela os direitos humanos ganharam preponderância no ordenamento social, foram aprimorados, caminharam do plano das ideias abstratas do pensamento filosófico para a fundamentalização constitucional. Salienta-se que os direitos ainda eram formais, a igualdade de gênero estava longe de ser reconhecida, e a igualdade racial ainda era uma pretensão a ser questionada.

Após a aprovação da Constituição Francesa, de 1791, a Assembleia Constituinte foi dissolvida, dando lugar apenas para a Assembleia Legislativa. Essa, em 1792, declarou guerra à Áustria e à Prússia, países que defendiam a restauração da ordem e dos direitos monárquicos na França. Com a derrota dos austríacos e prussianos e a declaração de que Luís XVI era inimigo da revolução, a Convenção Nacional francesa decretou o fim da Monarquia Constitucional, proclamando a República em 21 de setembro daquele mesmo ano. ${ }^{26}$

O poder de governo continuou sendo exercido pela Convenção Nacional, a qual elaborou uma nova Constituição, a de 24 de junho de 1793. ${ }^{27}$ O novo diploma, mesmo que fortemente influenciado pela Decla-

24 SÉNAT. Declaração dos Direitos do Homem e do Cidadão. Disponível em: http://www.senat.fr/lng/pt/declaration_droits_homme.html. Acesso em 7 de novembro de 2015.

25 SÉNAT. Constitution de $1791-3$ et 4 septembre 1791. Disponível em: http://www.conseil-constitutionnel.fr/conseil-constitutionnel/francais/la-constitution/lesconstitutions-de-la-france/constitution-de-1791.5082.html. Acesso em 7 de novembro de 2015.

${ }^{26}$ MOTA, Myriam Becho. História: das cavernas ao terceiro milênio. 2. vol. 1. ed. - São Paulo: Moderna, 2005. p. 130.

${ }^{27}$ SÉNAT. Constitution de l'An I - Première République - 24 juin 1793. Disponível em: http://www.conseilconstitutionnel.fr/conseilconstitutionnel/francais/laconstitution/lesconst ituions-de-la-france/constitution-du-24-juin-1793.5084.html. Acesso em 7 de novembro de 2015. 
ração de 1789, era muito mais radical. Com forte apelo social, já era possível ver naquela Constituição os sinais de direitos sociais, característicos da segunda dimensão dos direitos humanos, como exemplo, a disposição sobre o dever da sociedade em garantir a subsistência dos indivíduos em condições de miséria, Article 21 da Declaration des Droits de L'homme et du Citoyen.

Não obstante, a Constituição de 1793 praticamente não teve aplicação. Em razão da crise social, financeira e das guerras travadas pela França, foi estabelecido pelas lideranças da Convenção o governo provisório, conhecido como Terror. Entretanto, com os investimentos nas repressões dos questionadores do regime, o governo perdeu sua base anteriormente aliada, ensejando no golpe de Estado da alta burguesia, novo governo que seria chamado de Diretório.

Em 22 de agosto de 1795, foi promulgada outra Constituição pelo Diretório. ${ }^{28}$ A Carta, de cunho estritamente liberal, tinha como objetivo afastar os diferentes ideais dos antigos regimes, não observando as várias prerrogativas sociais anteriormente conquistadas. Porém, com o golpe de 18 Brumário, realizado em 9 de novembro de 1799, o poder governamental foi atribuído ao denominado Consulado, marco do que seria a era napoleônica. $^{29}$

As Declarações até agora mencionadas neste capítulo foram, sem dúvida, marcos do processo de evolução dos direitos humanos. Os primeiros diplomas amplamente consagrados de normas fundamentais formaramse na Inglaterra. Posteriormente, com as Declarações e Constituição dos Estados Unidos, teve início a primeira dimensão dos direitos fundamentais, de prestação estatal negativa, os quais também tiveram como marco a Declaração dos Direitos do Homem e do Cidadão, elaborada na França.

Com efeito, a evolução dos direitos humanos continuaria. $\mathrm{O}$ advento da Primavera dos Povos, a volta do ideário republicano na opinião pública e o vertiginoso crescimento da classe operária urbana foram fatores preponderantes para a Revolução Francesa de 1848. Nesses termos, a derrubada do governo monárquico francês ocorreu e, consequentemente, foi

${ }^{28}$ SÉNAT. Constitution de l'An III - Directoire - 5 fructidor An III, 22 août 1795. Disponível em: http://www.conseil-constitutionnel.fr/conseil-constitutionnel/francais/laconstitution/les-constitutions-de-la-france/constitution-du-5-fructidor-an-iii.5086.html. Acesso em 7 de novembro de 2015.

${ }^{29}$ MOTA, Myriam Becho. História: das cavernas ao terceiro milênio. 2. vol. 1. ed. - São Paulo: Moderna, 2005. p. 131-135. 
instaurada uma assembleia constituinte. Assim, em 4 de novembro de 1848 foi promulgada a nova Constituição, que marcaria o início da segunda dimensão dos direitos fundamentais. ${ }^{30}$

A Constituição Francesa de 1848 disciplinou boa parte dos direitos sociais pleiteados naquela época. A intervenção do estado na manutenção da subsistência digna do ser humano era a pretensão da sociedade. Assim, além da proteção dos direitos de liberdade e propriedade, o novo Documento assegurou a proteção ao trabalho, o alcance de cada um a instrução indispensável a todos os homens e, por assistência fraternal, na existência dos cidadãos necessitados, procurando-lhes trabalho ou, na falta de trabalho, prestando socorro àqueles que estavam sem condições de trabalhar.

Em 5 de fevereiro de 1917, foi promulgada outra Constituição de extrema relevância para a efetivação da segunda dimensão dos direitos fundamentais: a Constituição dos Estados Unidos Mexicanos. ${ }^{31}$ Tais fatos originaram-se de movimentos revolucionários no México, que reivindicavam direitos assistenciais, previdenciários, trabalhistas e de reforma agrária. Mesmo com a pouca fundamentalização dos direitos sociais, sua característica diferencial foi o lançamento das bases do Estado Social de Direito. ${ }^{32}$

A ascensão do Estado Social no século XX tornou-se eminente com a Constituição do Império Alemão, de 11 de agosto de 1919, conhecida como Constituição de Weimar. ${ }^{33}$ A grave situação social alemã, decorrente da Primeira Guerra Mundial, inspirou a elaboração dos direitos e deveres fundamentais dos alemães. A Carta de 1919 fundamentou um grande rol de direitos sociais, destacando-se a função social da propriedade, a reforma agrária, a ordem econômica e a proteção dos direitos trabalhistas e previdenciários. ${ }^{34}$

30 SÉNAT. Constitution de 1848, Ile République - 4 novembre 1848. Disponível em: http://www.conseil-constitutionnel.fr/conseil-constitutionnel/francais/la-constitution/lesconstitutions-de-la-france/constitution-de-1848-iie-republique.5106.html. Acesso em 7 de novembro de 2015.

${ }^{31}$ CÁMARA DE DIPUTADOS. Constitución Política de los Estados Unidos Mexicanos. Disponível em: http://www.diputados.gob.mx/LeyesBiblio/ref/cpeum/CPEUM_orig_ 05feb1917.pdf. Acesso em 8 de novembro de 2015.

${ }^{32}$ FERREIRA FILHO, Manoel Gonçalvez. Direitos humanos fundamentais. 12. ed. - São Paulo: Saraiva, 2010. p. 64.

${ }^{33}$ COMPARATO, Fábio Konder, 1936 - A afirmação histórica dos direitos humanos. 3. ed., rev. e ampl. - São Paulo: Saraiva, 2003. p. 192.

${ }^{34}$ Ibidem. p. 185. 
Destarte, os direitos de segunda dimensão nos mencionados diplomas ainda não abordavam de maneira necessária as questões de igualdade de gênero. A equiparação étnica e racial era meramente formal. A igualdade material, por meio da prestação positiva do Estado, envolvia questões de subsistência humana e privilégios masculinos. Exemplo profundo disso, dentre vários outros, era a manutenção do termo direitos dos homens na sociedade, como também, a vigência dos Estados colonizadores.

Por fim, a terceira dimensão dos direitos fundamentais veio disciplinar definitivamente as problematizações étnicas, raciais e de gênero concepção de sentido estrito na distinção dos sexos masculino e feminino. Porém, não se restringiu a isso: regulou o ordenamento pacífico e fraterno entre os povos por meio da ideia de direitos difusos.

A terceira dimensão/geração dos direitos humanos e fundamentais eclodiu após a Segunda Guerra Mundial, em razão da reflexão sobre as profundas barbaridades e resultados produzidos no conflito. O principal documento reconhecedor de tais reflexões foi aprovado pela Organização das Nações Unidas - ONU, criada em 24 de outubro de 1945, com o objetivo de proporcionar a paz mundial através do diálogo político, econômico e cultural das relações internacionais. ${ }^{35}$

Foi no ano de 1948, em 10 de dezembro, que a ONU promulgou a Declaração Universal dos Direitos Humanos, tendo por objetivo reconhecer a necessidade de proteção dos direitos dos povos e influenciar a fundamentalização dos direitos humanos nas constituições dos Estados. ${ }^{36} \mathrm{Na} \mathrm{De}-$ claração, é pregada a observância dos direitos difusos, como exemplo a proibição de qualquer tipo de discriminação racial, étnica e de gênero, o respeito à vida digna, à liberdade de pensamento e crença. O Documento também explicitou direitos sociais de segunda dimensão, são eles: direito ao trabalho, à saúde, à educação, entre outros.

É pertinente destacar outro Documento de extrema relevância aos direitos humanos e fundamentais, englobado na mencionada terceira dimensão: é a Convenção Americana sobre Direitos Humanos, também co-

\footnotetext{
35 ONU BRASIL. Conheça a ONU. Disponível em: http://nacoesunidas.org/conheca/. Acesso em 8 de novembro de 2015.

36 ONU BRASIL. Declaração Universal dos Direitos Humanos. Disponível em: http://e25.d32.myftpupload.com/img/2014/09/DUDH.pdf. Acesso em 8 de novembro de 2015.
} 
nhecida como Pacto de São José da Costa Rica. Subscrita em 22 de novembro de 1969, em São José da Costa Rica, e promulgada pelo Brasil em 6 de novembro de 1992, a Convenção constituiu à Corte Interamericana de Direitos Humanos e à Comissão Interamericana de Direitos Humanos a atuação instrumental para a proteção aos direitos humanos.

\section{CONSIDERAÇÕES FINAIS}

Conclui-se que os direitos fundamentais passaram por uma longa evolução, como ainda passam. As fontes materiais desses direitos foram e ainda são os anseios sociais que, posteriormente, são elevados ao status de direitos humanos.

Com efeito, as fontes materiais influenciam a feitura e consolidação das fontes formais precursoras, sendo os dois tipos de fontes do direito embasadoras basilares dos atuais direitos fundamentais.

Assim, é possível perceber que, para a aplicação eficaz dos atuais direitos, é necessário entender o processo de evolução dos direitos humanos e fundamentais, pois o sentido atual dessas normas é construído ao longo desse processo histórico e jurídico.

\section{REFERÊNCIAS BIBLIOGRÁFICAS}

AZAMBUJA, Darcy, 1903 - 1970. Teoria geral do Estado. 44. ed., São Paulo: Globo, 2003.

BONAVIDES, Paulo. Curso de Direito Constitucional. 9. ed. rev. atual. ampliada. (em apêndice texto da Constituição Federal de 1988, com a EC até a de n. 24, de 10.12.1999). São Paulo-SP: Malheiros, 2000. BRASIL. Promulga a Convenção Americana sobre Direitos Humanos (Pacto de São José da Costa Rica). Decreto n. 678, de 6 de Novembro de 1992. Brasília-DF: Presidência da República.

CÁMARA DE DIPUTADOS. Constitución Política de los Estados Unidos Mexicanos. Disponível em: http://www.diputados.gob .mx/LeyesBiblio/ref/cpeum/CPEUM_orig_05feb1917.pdf. Acesso em 8 de novembro de 2015 . 
COMPARATO, Fábio Konder, 1936 - A afirmação histórica dos direitos humanos / Fábio Konder Comparato. - 3. ed., rev. e ampl. - São Paulo: Saraiva, 2003.

A Afirmação Histórica dos Direitos Humanos. São Paulo: Saraiva, 1999, apud Biblioteca Virtual de Direitos Humanos, Universidade de São Paulo. Magna Carta - 1215 (Magna Charta Libertatum). Disponível em: http://www.direitoshumanos.usp. br/index.php/Documentos-anteriores-\%C3\%A0-cria\%C3\%A 7\%C3\%A3o-da-Sociedade-das-Na\%C3\%A7\%C3\%B5es-at\% C3\%A9-1919/magna-carta-1215-magna-charta-libertatum.ht ml. Acesso em 2 de novembro de 15.

DALLARI, Dalmo de Abreu, 1931 - Elementos de teoria geral do Estado. 20. ed. atual. - São Paulo: Saraiva, 1998.

DIPPEL, Horst. História do constitucionalismo moderno: novas perspectivas. Tradução de António Manuel Hespanha e Cristina Nogueira da Silva. Lisboa: Fundação Calouste Gulbenkian, 2007.

FERREIRA FILHO, Manoel Gonçalvez. Direitos humanos fundamentais. 12. ed. - São Paulo: Saraiva, 2010.

HOBBES, Thomas, 1588 - 1679. Do Cidadão; [tradução, apresentação e notas Renato Janine Ribeiro; coordenação Roberto Leal Ferreira] $2^{\circ}$ ed. - São Paulo: Martins Fontes, 1998. (Clássicos).

LEGISLATION.GOV.UK. Bill of Rights [1688]. Disponível em: http://www.legislation.gov.uk/aep/WillandMarSess2/1/2/introducti on. Acesso em 4 de novembro de 2015.

MACHADO, Antônio Alberto. Prisão cautelar e liberdades fundamentais. Rio de Janeiro: Lumen Juris, 2005.

MACHADO NETO, A. L. - Sociologia Jurídica. 6. Ed. - São Paulo: Saraiva, 1987.

MIRANDA, Pontes de. História e prática do habeas corpus; atualizado por Vilson Rodrigues Alves. - Campinas: Bookseller, 1999.

MONTORO, André Franco. 1916-1999. Introdução à ciência do direito. 28. ed. rev. e atual. - São Paulo: Editora Revista dos Tribunais, 2009.

MOTA, Myriam Becho. História: das cavernas ao terceiro milênio. 2. vol. 1. ed. - São Paulo: Moderna, 2005.

OLIVEIRA JÚNIOR, José Alcebíades de. Teoria jurídica e novos direitos. Rio de Janeiro: Lumen Juris, 2000.

ONU BRASIL. Conheça a ONU. Disponível em: http://nacoesunidas.org/conheca/. Acesso em 8 de novembro de 2015. 
. Declaração Universal dos Direitos Humanos. Disponível em: http://e25.d32.myftpupload.com/img/2014/09/DUDH.pdf. Acesso em 8 de novembro de 2015.

ROUSSEAU, J. J. - O contrato social. 3. Ed. - [tradução Danesi, A. P.]. São Paulo: Martins Fontes, 1996. (Clássicos).

SAMPAIO, José Adércio Leite. Direitos fundamentais: retórica e historicidade. Belo Horizonte: Del Rey, 2004.

SÉNAT. Constitution de l'An I - Première République - 24 juin 1793.

Disponível em: http://www.conseilconstitutionnel.fr/conseilconstitutionnel/francais /laconstitution/lesconstituions-de-la-france/constitution-du-24-juin1793.5084.html. Acesso em 7 de novembro de 2015.

. Constitution de l'An III - Directoire - 5 fructidor An III, 22 août 1795. Disponível em: http://www.conseil-constitutionnel.fr/conseilconstitutionnel/francais/la-constitution/les-constitutions-de-lafrance/constitution-du-5-fructidor-an-iii.5086.html. Acesso em 7 de novembro de 2015.

. Constitution de 1791 - 3 et 4 septembre 1791. Disponível em: http://www.conseil-constitutionnel.fr/conseilconstitutionnel/francais/la-constitution/les-constitutions-de-lafrance/constitution-de-1791.5082.html. Acesso em 7 de novembro de 2015.

. Constitution de 1848, Ile République - 4 novembre 1848. Disponível em: http://www.conseil-constitutionnel.fr/conseilconstitutionnel/francais/la-constitution/les-constitutions-de-lafrance/constitution-de-1848-iie-republique.5106.html. Acesso em 7 de novembro de 2015.

. Declaração dos Direitos do Homem e do Cidadão. Disponível em: http://www.senat.fr/lng/pt/declaration_droits_homme.html. Acesso em 7 de novembro de 2015.

THE LIBRARY OF CONNGRESS, Bill of Rights. Disponível em: http://www.loc.gov/rr/program/bib/ourdocs/billofrights.html. Acesso em 4 de novembro de 2015.

TRINDADE, Antônio Augusto Cançado. Direitos humanos e meioambiente: paralelo dos sistemas de proteção internacional. Porto Alegre: Sergio Antonio Fabris Editor, 1993.

VASAK, Karel. The international dimensions of Human Rights. Paris, Unesco, 1982. 
WHITE HOUSE. The Constitution of the United States of America. Disponível em: https://www.whitehouse.gov/1600/constitution. Acesso em 4 de novembro de 2015. 